ALI G. GHAWI, J. KRIŠ

\section{IMPROVEMENT PERFORMANCE OF SECONDARY CLARIFIERS BY A COMPUTATIONAL FLUID DYNAMICS MODEL}

\section{ABSTRACT}

Secondary clarifier is one of the most commonly used unit operations in wastewater treatment plants. It is customarily designed to achieve the separation of solids from biologically treated effluents through the clarification of biological solids and the thickening of sludge. As treatment plants receive increasingly high wastewater flows, conventional sedimentation tanks suffer from overloading problems, which result in poor performance. Modification of inlet baffles through the use of an energy dissipating inlet (EDI) was proposed to enhance the performance in the circular clarifiers at the Al-Dewanyia wastewater treatment plant. A 3-dimensional fully mass conservative clarifier model, based on modern computational fluid dynamics theory, was applied to evaluate the proposed tank modification and to estimate the maximum capacity of the existing and modified clarifiers. A Computational Fluid Dynamics (CFD) model was formulated to describe the tank is performance, and design parameters were obtained based on the experimental results. The study revealed that velocity and (suspended solids) SS is a better parameter than TS (total solids), (Biochemical Oxygen Demand) $B O D$, (Chemical Oxygen Demand) COD to evaluate the performance of sedimentation tanks and that the removal efficiencies of the suspended solids, biochemical oxygen demand, and chemical oxygen demand were higher in the baffle.

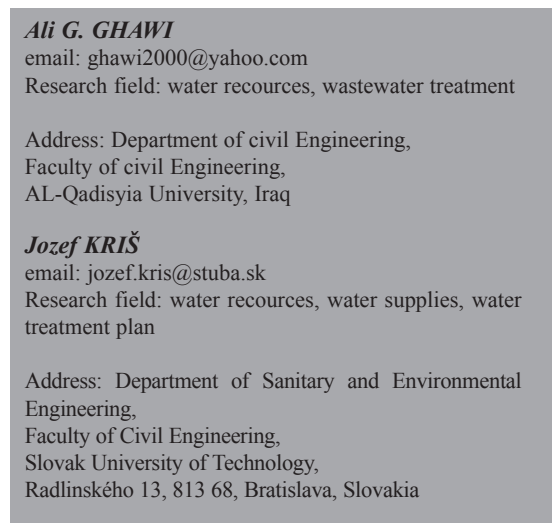

\section{KEY WORDS}

- Clarifier

- Sedimentation

- Sludge

- Wastewater

- Solids

- $C F D$

\section{INTRODUCTION}

In wastewater treatment plants as well as in a variety of industrial processes, sedimentation tanks are used to separate suspended solids from water. Sedimentation by gravity is the most common and extensively applied treatment process for the removal of solids from water and wastewater. The increasing concern which is being voiced as to the destruction and pollution of our environment has produced a growing awareness worldwide of the need for more effective wastewater treatment. In addition, the contribution of effluents and sludge to the spread of many types of human and animal infections is now being quantified. This has emphasized the vital need for improved water supplies and sanitation, especially in developing countries. The operation of wastewater treatment works are therefore no longer the exclusive domain of the engineer and chemist; multidisciplinary teams of engineers and scientists are required in order to maximize the benefits to the community which should occur from the installation of sewage treatment. In modern societies proper management of wastewater is a necessity, not an option. Wastewater collected from municipalities and communities must ultimately be returned to receiving waters or to the land. The complex question of which contaminants in wastewater must be 


\section{IDYALS JOUSSILL \\ 0)

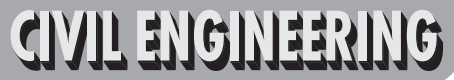

2011/4 PAGES $1-11$

removed to protect the environment - and to what extent - must be answered specifically for each case. The answer to this question requires analyses of local conditions and needs, together with the application of scientific knowledge, economic analysis, and engineering judgment based on past experience and consideration of national requirements and regulations.

Upgrading of existing wastewater treatment plants (WWTPs) may become necessary for a variety of reasons. Growth within the service area, or the desire to serve additional areas, may result in the need to increase the capacity of an existing treatment facility. New, more stringent requirements may be imposed on a treatment facility, resulting in a need to upgrade treatment processes. Older facilities may need upgrading to replace existing equipment that no longer functions as intended or to allow installation of newer, more efficient and cost-effective technology. In this case, the objective of the upgrading may be to improve plant reliability or / and reduce operating cost. Of course, more than one of these reasons may combine for a particular plant. The subject of upgrading existing wastewater plants is particularly important at this time. It is important both because of the large number of existing facilities and because of the increasingly stringent requirements imposed on wastewater treatment facilities. A number of studies have investigated sediment distribution and flow patterns in sedimentation tanks and clarifiers. Several of the studies (Krebs [1], Dahl, et al. [2], Krebs, et al. [3], Brouckaert and Buckley [4]. Lakehal, et al. [5], Jayanti and Narayanan [6], Ghawi and Kris [7, 8, and 9], have been carried out using the CFD model.

The CFD study of a secondary clarifier at the Al-Dewanyia Wastewater Treatment Plant in Iraq was undertaken with a view to improving its capacity to retain sludge under high hydraulic load conditions, which has come under pressure due to the growth in the provision of services.

The objective of this study is to examine the possibility of upgrading conventional secondary clarifiers in an operating wastewater
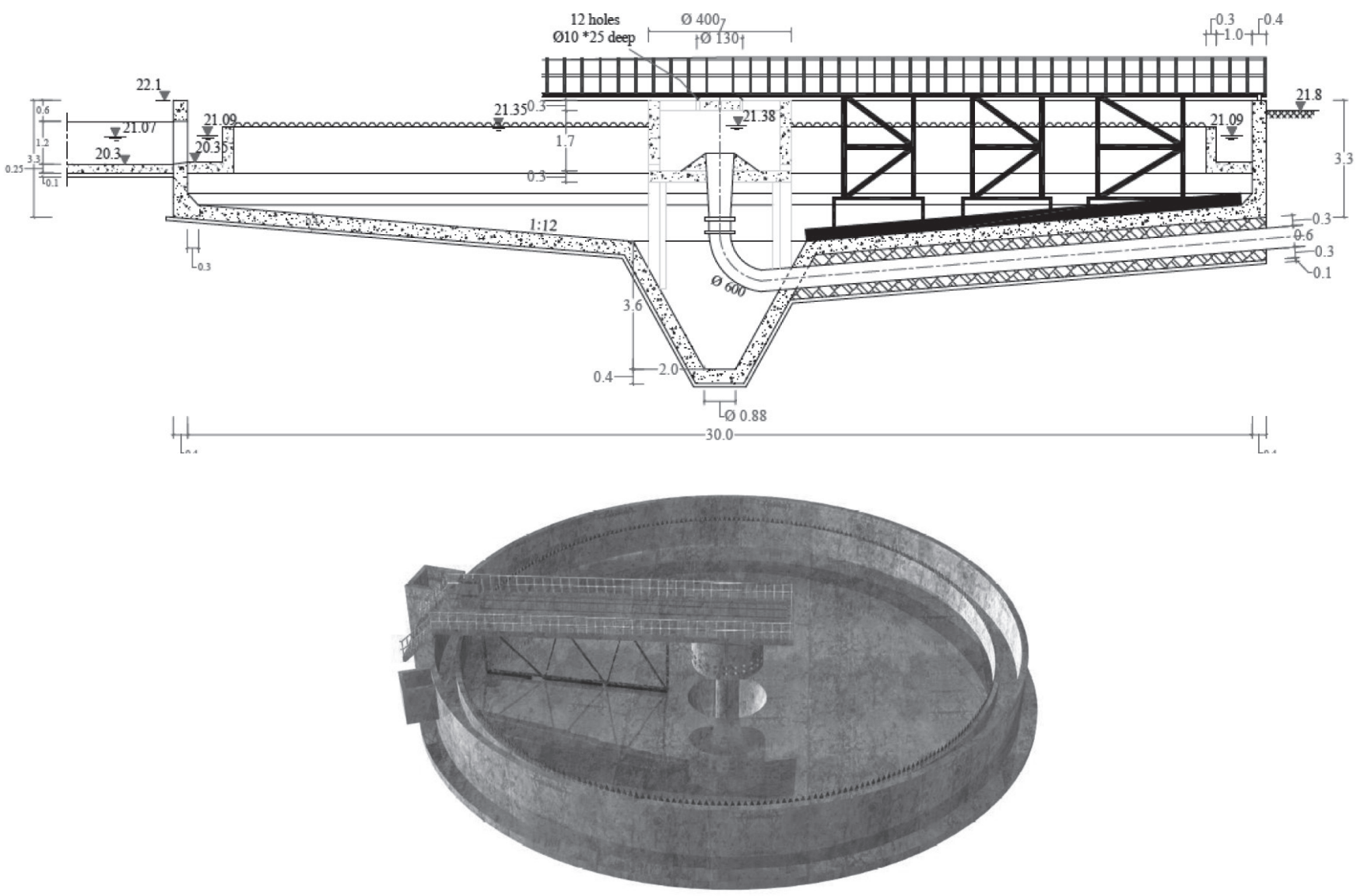

Fig. 1 Clarifier scheme at Al-Dewanyia Wastewater Treatment Plant. 
2011/4 PAGES $1-11$

treatment plant by applying an energy dissipating inlet (EDI) (baffle) for the clarifier inlet. In order to achieve such objectives, field experiments and a mathematical model (CFD model) were conducted at the main wastewater treatment plant in Al-Dewanyia using sedimentation tanks with and without EDI for secondary clarification of activated-sludge mixed liquor.

\section{MATERIALS AND METHODS}

There are two secondary clarifiers at the Al-Dewanyia Wastewater Treatment Plant. These are circular with a $30 \mathrm{~m}$ diameter by $3.0 \mathrm{~m}$ deep wall and are centrally fed. Each unit is nominally designed to handle $250 \mathrm{~m}^{3} / \mathrm{hr}$ flow, with an equal flow rate of sludge recycled to the activated sludge plant. The clarifiers at these plants are centre-feed and peripheral-overflow clarifiers (Figure 1) designed for optimum activated sludge secondary clarifier performance. The tank geometry and operating conditions for both clarifiers are summarized below:

Clarifier diameter $=30 \mathrm{~m}$

Side wall depth $=3.0 \mathrm{~m}$

Peak Day Conditions: Influent Flow $=18,000 \mathrm{~m}^{3} / \mathrm{d}=750 \mathrm{~m}^{3} / \mathrm{h}$, $\mathrm{MLSS}=3,000 \mathrm{mg} / \mathrm{L}$,

RAS Flow $=7,500 \mathrm{~m}^{3} / \mathrm{d}=312,5 \mathrm{~m}^{3} / \mathrm{h}$

Surface Overflow Rate $(\mathrm{SOR})=\mathbf{1 . 3} \mathrm{m} / \mathrm{h}$

Solids Loading Rate $($ SLR $)=\mathbf{1 3 2 . 6} \mathrm{kg} / \mathrm{m}^{2} /$ day

"Typical" Settling Characteristics (from an example site with an SVI of approximately $150 \mathrm{~mL} / \mathrm{g}$ )

The performance and capacity of a center-feed clarifier is very sensitive to the intensity of the influent jets entering the clarifiers. A center-feed clarifier naturally generates a strong influent jet due to its small center-feed area in a circular clarifier tank as shown in Figure 1. The intensive center influent often brings significant turbulence into the settling compartment, especially under high flow conditions. To enhance the hydraulic efficiency and capacity of the center-feed clarifiers, one of the most important key issues is to develop a center-feed apparatus, which could be used to effectively reduce the intensity of the central influent jet and turbulence under high-flow conditions.

To enhance the hydraulic efficiency and capacity of the center feed clarifiers, the key is to develop a new center feed structure, which could be used to effectively reduce the strength of the center influent jet under high-flow conditions. To estimate the performance enhancements resulting from the use of an energy dissipating inlet (EDI) in a circular clarifier, a set of computational fluid dynamics (CFD) calculations were performed (Figure 2). In the first simulation, the flow through a clarifier equipped with
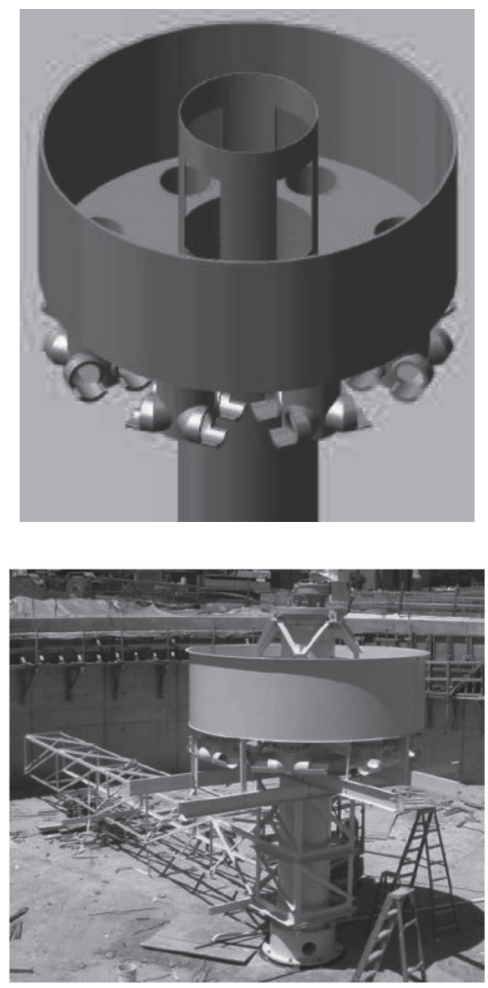

Fig. 2 Modified center inlet structure (EDI).

a center inlet pipe and open centerwell was calculated. In the second simulation, the center inlet pipe was replaced with an EDI. Details regarding the development of the CFD model are given in the next section.

The CFD calculations provide estimates of the solid effluent concentrations, return activated sludge (RAS) concentrations, sludge blanket depth and flow distributions in the clarifiers. Performance comparisons were made on the basis of these calculated parameters. Using the traditional influent structure (as shown in Figure 2), the jet of the clarifier influent through the influent slots is very strong due to the very small cross sectional area of the slots. However, if the cross sectional area of the inlet slots is simply enlarged, flow short-circuiting (or unevenly distributed flow) may occur among the slots. To design the EDI, the flocwell diameter was $7.9 \mathrm{~m}$ and the depth $1.5 \mathrm{~m}$. Figure 2 shows the actual EDI geometry that was tested.

The wastewater treatment plant was operated at different flow rates to determine the effect of Hydraulic Retention Time (HRT) and Surface Loading Rate (SLR) on the performance of the clarifier. Influent and effluent samples were collected at different operating periods. The liquid temperature ranged from $23-29{ }^{\circ} \mathrm{C}$ during the 
experiment. The samples were analyzed according to procedures outlined in "Standard Methods For The Examination of Water and Wastewater", 17th edition, APHA, (1989) [10] to determine the following parameters: Suspended Solids (SS), Total Solids (TS), Biochemical Oxygen Demand (BOD), Chemical Oxygen Demand (COD), Volatile Suspended Solids (VSS), Total Volatile Solids (TVS) and Settleable Solids.

\section{CFD MODELLING}

Several computer software programs have been developed for Computational Fluid Dynamic (CFD) modelling. In this study FLUENT 6.3 and the 3D k- $\varepsilon$ turbulence model in the Environmental Engineering Module was used. During this study the hydraulic CFD modelling began with the definition of the settling tank geometry. Secondly, fluid characteristics and boundary conditions were defined. The momentum balance, including the turbulence model and continuity equations, were then solved numerically for the tank using the finite volume method. Finally, the obtained solution was post-processed to be properly visualised. Common mathematical hydraulic model equations used for CFD modelling include the momentum balances for a non-compressible viscous media and the continuity equation [11].

$\rho \frac{\partial U}{\partial t}-\nabla\left[\left(\mu+\rho C \mu \frac{k^{2}}{\varepsilon}\right)\left(\nabla U+(\nabla U)^{T}\right)\right]+\rho U \cdot \nabla U+\nabla P=F$

$\nabla \cdot U=0$

In the settling model an additional scalar equation was added to include the concentration of the solids. This convection-diffusion equation is as follows:

$\rho \frac{\partial C}{\partial t}+\frac{\partial \rho\left(U+U_{S}\right) C}{\partial x_{i}}=\rho \frac{\partial}{\partial x_{i}}\left(\frac{v_{t}}{\sigma_{c}} \frac{\partial C}{\partial x_{i}}\right)$

The settling velocity was modelled using the Takács exponential settling function, this expression being introduced in the resolution of the concentration equation.

$U_{S}=U_{S 0} X \exp \left[-r_{h}\left(C-U_{n s}\right)\right]-U_{S 0} X \exp \left[-r_{p}\left(C-U_{n s}\right)\right]$

The standard k- $\varepsilon$ eddy-viscosity model was used to account for the turbulent effects. The turbulent viscosity was defined as a function of the turbulent kinetic energy $\mathrm{k}$ and its dissipation rate $\varepsilon$ by the equation: $\mu_{t}=\rho C_{\mu} \frac{k^{2}}{\varepsilon}$

The distributions of $\mathrm{k}$ and $\varepsilon$ were determined from the following transport equations:

$$
\begin{aligned}
& \frac{\partial \rho k}{\partial t}+\frac{\partial k}{\partial x_{i}}\left(\rho k u_{i)}=\frac{\partial}{\partial x_{j}}\left(\left(\mu+\frac{\mu_{t}}{\sigma_{k}}\right) \frac{\partial k}{\partial x_{i}}\right)+\right. \\
& +G_{k}+G_{b}-\rho \varepsilon-Y_{M}+S_{k} \\
& \frac{\partial \rho \varepsilon}{\partial t}+\frac{\partial k}{\partial x_{i}}\left(\rho \varepsilon u_{i)}=\frac{\partial}{\partial x_{j}}\left(\left(\mu+\frac{\mu_{t}}{\sigma_{\varepsilon}}\right) \frac{\partial \varepsilon}{\partial x_{i}}\right)+\right. \\
& +C_{k} \frac{\varepsilon}{k}\left(G_{k}+C_{s c} G_{b}\right)-C_{2 \varepsilon} \rho \frac{\varepsilon^{2}}{k}+S_{\varepsilon}
\end{aligned}
$$

The model constants $\left(\mathrm{C}_{\mu}, \mathrm{C}_{\varepsilon 1}, \mathrm{C}_{\varepsilon 2}, \sigma_{k}, \sigma_{\mathrm{e}}\right)$ in the above equations have been determined from experimental data and are set to the standard parameters [11]:

$\mathrm{C}_{\mu}=0.09, \mathrm{C}_{\varepsilon 1}=0.1256, \mathrm{C}_{\varepsilon 2}=1.92, \sigma_{k}=0.9, \sigma_{\varepsilon}=1.3$

$\mathrm{G}_{\mathrm{b}}$ describes the influence of the buoyancy effects and is defined as a function of the suspended solids concentration gradient:

$G_{b}=\beta g \frac{v_{t}}{\sigma_{c}} \frac{\partial C}{\partial x}=\frac{\rho_{p}-\rho_{w}}{\rho_{p} \rho_{w}} g \frac{v_{t}}{\sigma_{c}} \frac{\partial C}{\partial x}$

The concentration gradient, which reaches maximum values at the interface between the clear fluid and the sludge blanket, hinders turbulence. The source term $\mathrm{G}_{\mathrm{b}}$ introduced in the turbulence equation addresses this matter. The value of $\mathrm{C}_{3 \varepsilon}$, usually reported as constant, varies with the ratio of the gravity direction parallel flow velocity with respect to the perpendicular flow velocity:

$C_{S C}=\tanh \left|\frac{v}{u}\right|$

The later expression yields values close to a unity for the unstable areas, and tends towards zero for the stratified sedimentation. A Boussinesq-type approach also implies that the effect of sludge gravity is introduced implicitly as a function of the concentration of suspended solids. Its implementation in the momentum equations is carried out by means of the source terms:

$g\left(\rho_{p}-\rho_{w}\right)=g C \frac{\rho_{p}-\rho_{w}}{\rho_{p}}$

The dependence of the viscosity on the concentration is empirically input at different concentration ranges. The effect of the scraper blades has been usually either neglected or introduced as uniform 
constant sources, especially in the modelling of a circular sedimentation tank. However, due to the significance of the scraper system for a circular sedimentation tank, an additional sub-model was incorporated to better model the effects of the transport of solids. The conveying force exerted on the fluid was approximated as a function of fluid the velocity, including a flow regimedependent drag coefficient:

$F_{D}=C_{D} \frac{1}{2} \rho A V_{r}^{2}$

Different flow rates were used in each continuous experiment during which several samples were collected from the influent and effluent of the tank. The samples were analyzed to determine suspended solids, total solids, biochemical oxygen demand and chemical oxygen demand. In addition, some samples were taken from the settled sludge to determine the concentration of solids.

\subsection{Boundary Conditions}

All the boundaries corresponding to the concrete surfaces were modelled using the wall functions provided by FLUENT, with a surface roughness parameter set to $0.5 \mathrm{~mm}$. The free liquid surface was represented as a rigid frictionless surface. The flow boundary conditions were set by specifying the mass withdrawal rates. Thus the overflow rates were specified at the computational cells, and the underflow rate was distributed over a row of cells corresponding to the sludge withdrawal area. The feed inlet to the clarifier was allowed to satisfy the material balance by specifying a fixed pressure at the cells corresponding to the location of the feed slots. Flow rates to be used in the model were determined from measurements conducted on the clarifier on 10 July 2009.

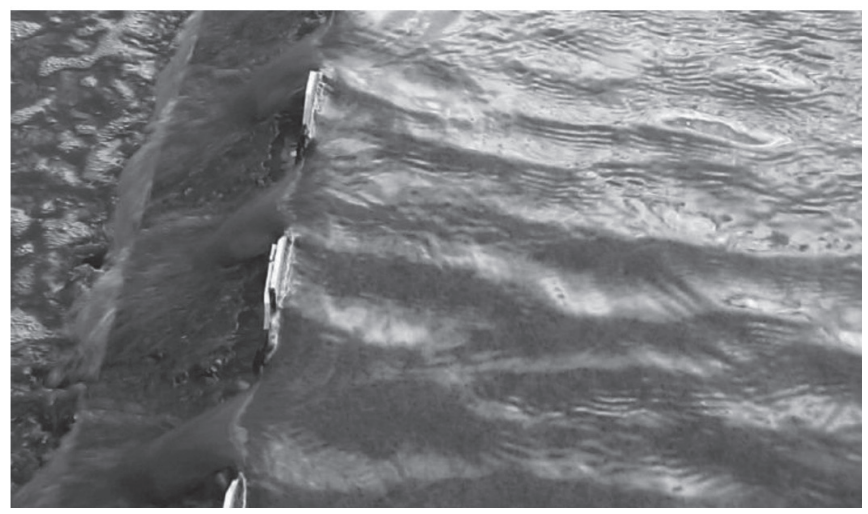

Fig. 3 Overloaded clarifier operations.

\section{EXISTING CLARIFIER PERFORMANCE}

As shown in Figure 3, the existing secondary clarifiers at the Al-Dewanyia Wastewater Treatment Plant, often experience a very high effluent TSS due to the impact of a massive sludge inventory. In the overloaded clarifiers, the effluent TSS (and BOD) is extremely sensitive to any minor variations in the plant flow. This is because the top of the sludge blanket is close to the surface and can easily be carried over the effluent weirs. The overloaded conditions can often cause a large unexpected loss of bio-solids from the secondary treatment process.

The flow capacity for the two existing clarifiers studied ranges from 500 to $750 \mathrm{~m}^{3} / \mathrm{hr}$ due to variations in the process parameters (MLSS). The clarifiers are unable to achieve their expected design flow of $750 \mathrm{~m}^{3} / \mathrm{hr}$ due primarily to the thickening limitation of the clarifiers. The performance and capacity of a center feed clarifier is very sensitive to the strength of the influent jets into the clarifiers. A traditional center feed clarifier naturally generates a strong influent jet due to its small center feed area. Thus, it often brings significant turbulence into the settling compartment, especially under high flow conditions.

The experiments consisted of five runs with different influent flow rates to the simulate actual operating conditions of the secondary clarifier in the plant. Each continuous run lasted for a minimum of 5 hours. The influent to the clarifier was the mixed liquor from the second compartment of a high rate aeration tank at the Al-Dewanyia sewage treatment plant. The operating conditions during the testing period are presented in Table $\mathbf{1 .}$

From the above table it is clear that there were not many fluctuations in the influent characteristics, i.e. the mixed liquor suspended Solids (MLSS), which could affect the performance of the tank during testing period. Similar to the efficiency of SS removal, the BOD and COD removal efficiencies were more or less constant during the operating period at each flow rate. This emphasizes that the

Tab. 1 Operating conditions during conventional settling tank experiment.

\begin{tabular}{|c|c|c|c|c|c|}
\hline $\mathbf{Q}$ & HRT $^{*}$ & MLSS & SVI & \multicolumn{2}{|c|}{ Temperature, $\left({ }^{\circ} \mathbf{C}\right)$} \\
\hline $\left.\mathbf{( m}^{\mathbf{3}} / \mathbf{h r}\right)$ & (hour) & $\mathbf{( \mathbf { m g } / \mathbf { l } )}$ & $\mathbf{( \mathbf { m l } / \mathbf { g } )}$ & Liquid & Air \\
\hline 150 & 2.17 & 2085 & 149 & 29.0 & 33.8 \\
\hline 200 & 0.87 & 2170 & 148 & 24.8 & 28.6 \\
\hline 250 & 0.65 & 2770 & 130 & 30.0 & 33.6 \\
\hline 300 & 0.47 & 3120 & 131 & 30.6 & 34.3 \\
\hline 350 & 0.33 & 2390 & 125 & 27.0 & 30.6 \\
\hline
\end{tabular}

* HRT : Hydraulic Retention Time 
Tab. 2 Performance of conventional settling tank in SS and TS removal.

\begin{tabular}{|c|c|c|c|c|}
\hline $\begin{array}{c}\mathbf{Q} \\
\left(\mathbf{m}^{\mathbf{3}} \mathbf{h r} \mathbf{)}\right)\end{array}$ & $\begin{array}{c}\text { HRT } \\
(\mathbf{h o u r})\end{array}$ & $\begin{array}{c}\mathbf{q}=\text { SLR }=\text { SOR } \\
\left(\mathbf{m}^{\mathbf{3}} / \mathbf{m}^{\mathbf{2}} \mathbf{. h r} \mathbf{)}\right.\end{array}$ & $\begin{array}{c}\text { SS removal } \\
\mathbf{( \% )}\end{array}$ & $\begin{array}{c}\text { TS removal } \\
\mathbf{( \% )}\end{array}$ \\
\hline 150 & 15.54 & 0.26 & 94.8 & 59.6 \\
\hline 200 & 11.66 & 0.35 & 94.7 & 67.4 \\
\hline 250 & 9.33 & 0.43 & 94.1 & 62.0 \\
\hline 300 & 7.77 & 0.52 & 93.6 & 66.0 \\
\hline 350 & 6.66 & 0.61 & 94.1 & 68.1 \\
\hline
\end{tabular}

tank performance was stable during the period studied. Also, the relationship between (Hydraulic Retention Time) HRT and the removal efficiency of both SS and TS is shown in Table 2 and Figure 4.

It is clear from Figure 4 that while the $\% \mathrm{SS}$ removed increased as the HRT increased, the \% TS did not show a similar trend since the \% TS was almost constant, if not slightly decreasing, as HRT was increased. This may indicate that biological activities took place in the sedimentation tank, especially during longer HRTs, thus transforming the biological SS into dissolved solids. Such transformations would ultimately increase the TS concentration during longer HRTs, i.e. , decrease the $\%$ TS removal efficiency. This emphasizes the importance of evaluating sedimentation tank performance based on SS (rather than TS) as is usually reported in the literature. The effect in the case of the relationship between the SLR and the removal efficiency of SS and TS is contrary to that observed for HRT as shown in Table 2 and Figure 5.

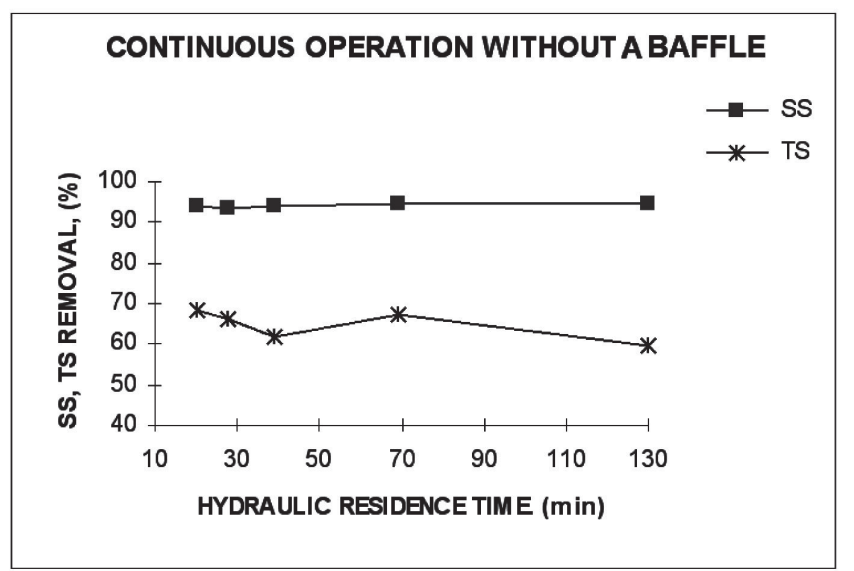

Fig. 4 Performance of conventional settler at different hydraulic residence times.

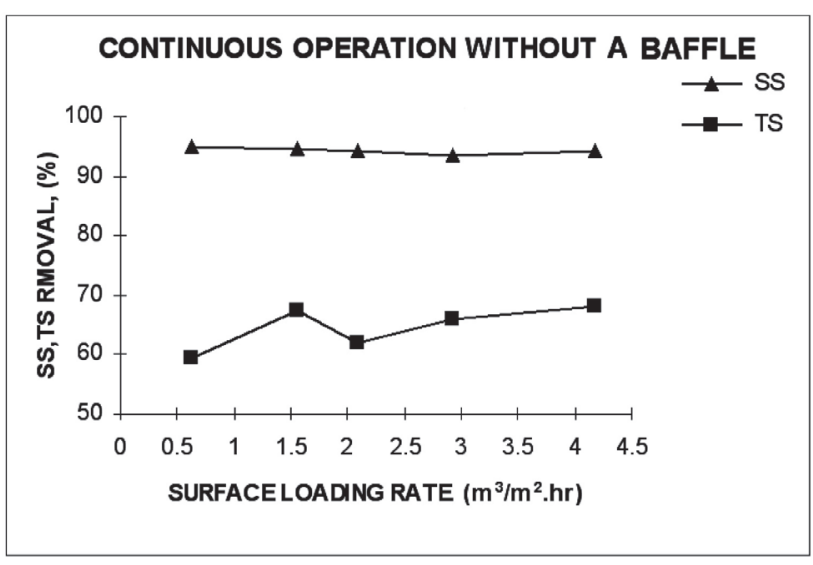

Fig. 5 Performance of conventional settler at different surface loading rates.

The good performance of the sedimentation tank during this study is possibly due to the good settleability of the biological solids as indicated by the Sludge Volume Index (SVI) values being in the optimum range of $(125-149 \mathrm{ml} / \mathrm{g})$ as presented in Table 1 .

\section{RESULT AND DISSOCIATION}

\subsection{Performance of Clarifiers with an Optimized Influent Structure}

Figure 6 presents comparison of the Computational Fluid Dynamic (CFD) modelling results for flow and solids fields between the centre-feed clarifier described in Figure 1, in which there is no energy dissipating apparatus around the vertical centre-feed pipe.

Figures 6(a) and 6(b) present the velocity and solids fields in a selected vertical slice of the tested clarifiers. In the model predicted velocity fields, each velocity vector originates at a grid point used in the CFD model. The length of each vector is proportional to the magnitude of the velocity determined by the model for the corresponding grid point, and is in accordance with the $3.0 \mathrm{~cm} / \mathrm{s}$ scale indicated in the figures. The figures also present he simulated solids fields in an identical vertical section of the model. In this figure the contour lines with interval of $100 \mathrm{mg} / \mathrm{L}$ indicates the Suspended Solids concentration.

In a centre-feed clarifier, it is not very easy to enforce flow evenly entering the clarifier along the rim of an energy dissipating column unless enough resistance along the radial direction can be created within the device. However, the high resistance along the radial direction can not be generated through simply reducing the size or number of the inlet ports, which would increase the flow intensity 


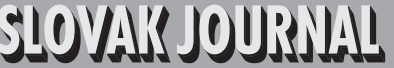

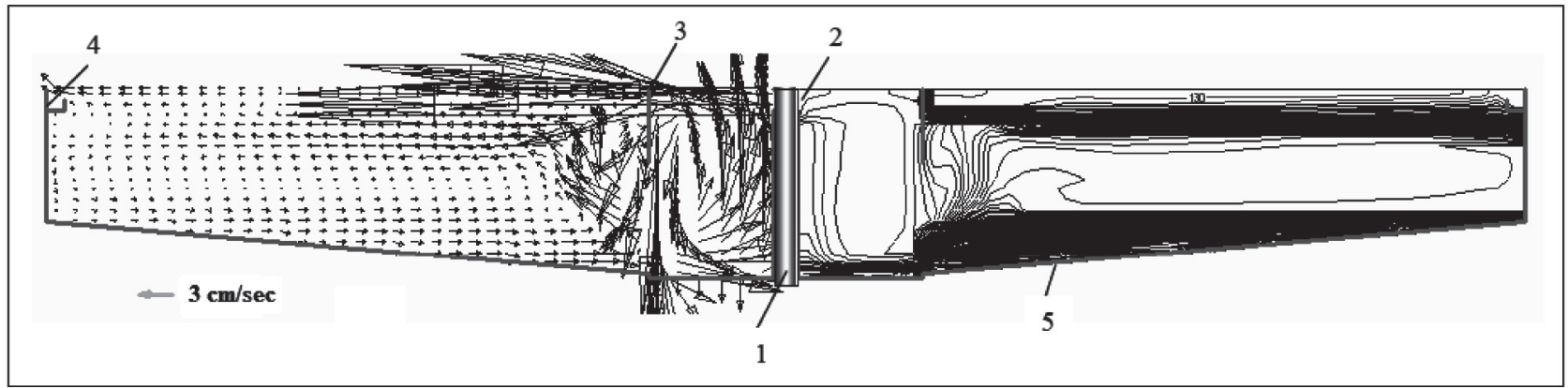

a) Existing Clarifier

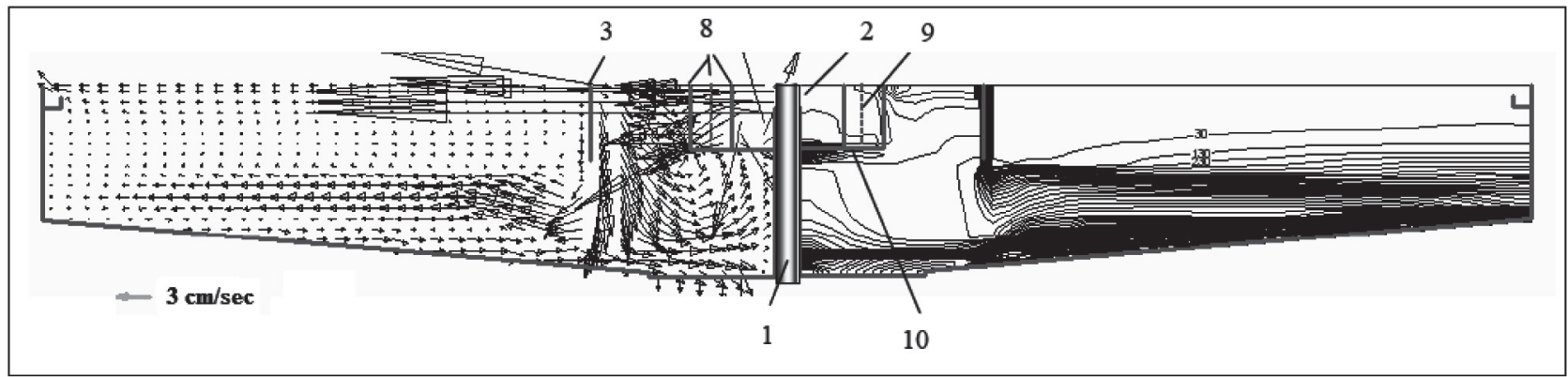

b) Modified Clarifier

Fig. 6 Performance before (a) and after (b) central inlet retrofit.

entering into the clarifiers. The EDI is able to simultaneously satisfy both of the energy dissipating principles, i.e. a large accumulative space of inlet ports and a uniform flow distribution among all of the inlet ports due to the multilayer flow impingement.

Figure 6 consists of the two parts of $\mathbf{6}(\mathbf{a})$ and $\mathbf{6}(\mathbf{b})$ with respect to the two tested clarifiers with and with no the EDI, respectively.

As shown in Figure 6(a), the CFD modelling results for the clarifier equipped with a simple centre influent pipe indicate:

1. The strong influent jet through the inlet ports (2) penetrates the entire radius of the flocculation well (3) and impinges on the inner side of the well (3) due to the lack of effective momentum/ energy dissipating facilities within the flocculation well. After impinging on the flocculation well, the influent flow deflects and forms a very strong downward current toward the sludge blanket and clarifier floor (5).

2. Significant reverse flow is predicted underneath the strong surface influent jet due to the shears between them.

3. A pinched clarifier influent flow under the baffle lip (3) can be observed due to the massive sludge inventory in the clarifier.
The density of the forward current is much closer to the water surface than that predicted under a lower flow condition due to the buoyancy impact of the thick sludge blanket.

As shown in Figure 6(b), the modelling results for the clarifier equipped with a EDI (8) indicate:

1. Due to the small influent ports the strong influent jet (2) continuously impinges on the multilayer perforated columns (8) one after the other. The velocities of the influent jets have been substantially reduced before and after going through the ports (9) in the last perforated layer (8). The resistance created by the multiple perforated columns (8) forces the influent jet to be sufficiently distributed along the vertical and tangential directions before it enters into the flocculation well (3).

2. Due to The downward current the deflection of the influent jet on the flocculation well (3), has been significantly reduced, since the momentum of the influent jet is effectively dissipated by applying the EDI. The circular bottom (10) forces all of the influent flow to go through the staggered ports (9) and prevents 
the flow from short circuiting between the inlet ports (2) and flocculation well (3).

3. The pinched flow underneath the lip of the baffle (flocculation well) (3) has been eliminated, and the level of the density of the forward current is much closer to the clarifier floor (5) due to the lowered turbulence and the well controlled dispersed sludge blanket in the clarifier.

4. The significant reverse flow underneath the surface influent jet predicted in the existing clarifiers has been almost eliminated, since the significantly slowed influent jet generates a much weaker shear influence on the ambient flow.

The existing clarifiers have flow capacities of approximately 750 $\left(\mathrm{m}^{3} / \mathrm{h}\right)$ under the normal process condition, which is most of the year. The optimized clarifiers can achieve a flow capacity of around $1300\left(\mathrm{~m}^{3} / \mathrm{h}\right)$, which is $30 \%$ higher than that of the existing clarifiers. The performance of the EDI (Baffle) was examined by applying nine different influent flow rates ranging from $150 \mathrm{~m}^{3} / \mathrm{hr}$ to

Tab. 3 Operating conditions during EDI (Baffle) experiment.

\begin{tabular}{|c|c|c|c|c|c|}
\hline \multirow{2}{*}{$\begin{array}{c}\mathbf{Q} \\
\left(\mathbf{m}^{\mathbf{3}} \mathbf{h r}\right)\end{array}$} & $\begin{array}{c}\text { HRT } \\
\text { (hour })\end{array}$ & $\begin{array}{c}\text { MLSS } \\
(\mathbf{m g} / \mathbf{l})\end{array}$ & \multirow{2}{*}{$\begin{array}{c}\text { SVI } \\
(\mathbf{m l} / \mathbf{g})\end{array}$} & \multicolumn{2}{|c|}{ Temperature, $\left({ }^{\circ} \mathbf{C}\right)$} \\
\hline 150 & 2.04 & 1735 & 116 & 24.7 & 25.2 \\
\hline 175 & 1.22 & 2470 & 122 & 28.8 & 29.3 \\
\hline 200 & 0.82 & 2172 & 461 & 22.2 & 27.2 \\
\hline 225 & 0.61 & 1784 & 476 & 21.9 & 27.6 \\
\hline 250 & 0.51 & 2256 & 147 & 22.2 & 28.0 \\
\hline 275 & 0.44 & 2308 & 208 & 23.5 & 27.9 \\
\hline 300 & 0.38 & 1561 & 547 & 21.7 & 28.1 \\
\hline 325 & 0.34 & 2494 & 128 & 24.9 & 27.9 \\
\hline 350 & 0.31 & 2093 & 107 & 23.8 & 26.8 \\
\hline
\end{tabular}

Tab. 4 Performance of EDI (Baffle) in SS and TS removal.

\begin{tabular}{|c|c|c|c|c|}
\hline $\begin{array}{c}\mathbf{Q} \\
\left(\mathbf{m}^{\mathbf{3}} \mathbf{h r} \mathbf{)}\right.\end{array}$ & $\begin{array}{c}\text { HRT } \\
(\mathbf{m i n})\end{array}$ & $\begin{array}{c}\text { SLR } \\
\left(\mathbf{m}^{\mathbf{3}} / \mathbf{m}^{\mathbf{2}} \mathbf{. h r}\right)\end{array}$ & $\begin{array}{c}\text { SS removal } \\
(\mathbf{\%})\end{array}$ & $\begin{array}{c}\text { TS removal } \\
(\mathbf{\%})\end{array}$ \\
\hline 150 & 2.04 & 0.24 & 97.7 & 56.1 \\
\hline 175 & 1.22 & 0.28 & 97.5 & 69.2 \\
\hline 200 & 0.82 & 0.36 & 97.9 & 54.6 \\
\hline 225 & 0.61 & 0.39 & 97.5 & 43.8 \\
\hline 250 & 0.51 & 0.425 & 97.1 & 64.2 \\
\hline 275 & 0.44 & 0.461 & 96.7 & 47.6 \\
\hline 300 & 0.38 & 0.52 & 94.7 & 46 \\
\hline 325 & 0.34 & 0.563 & 97.2 & 64.8 \\
\hline 350 & 0.31 & 0.607 & 96.2 & 66.1 \\
\hline
\end{tabular}

$350 \mathrm{~m}^{3} / \mathrm{hr}$ in separate mathematical model runs. The duration of each continuous run was at least 5 hours, during which different samples were collected from the influent and effluent of the tank. The main parameters (i.e. SS, TS, BOD, etc.) were determined, and the removal efficiencies were calculated at different influent flow rates. The performance was stable during each operating period studied. The values of HRT in the tank were calculated for each mathematical model run as illustrated in Table 3, and the corresponding SLR values are presented in Table 4.

The relationships between HRT and the removal efficiencies of both the SS and TS were established as presented in Figure 7, from which it is clear that the removal efficiency increases as the HRT increases. Figure 8 shows the relationship between the SLR and removal efficiencies for both the SS and TS. It is evident that the efficiency of the removal decreases as SLR increases. Such trends

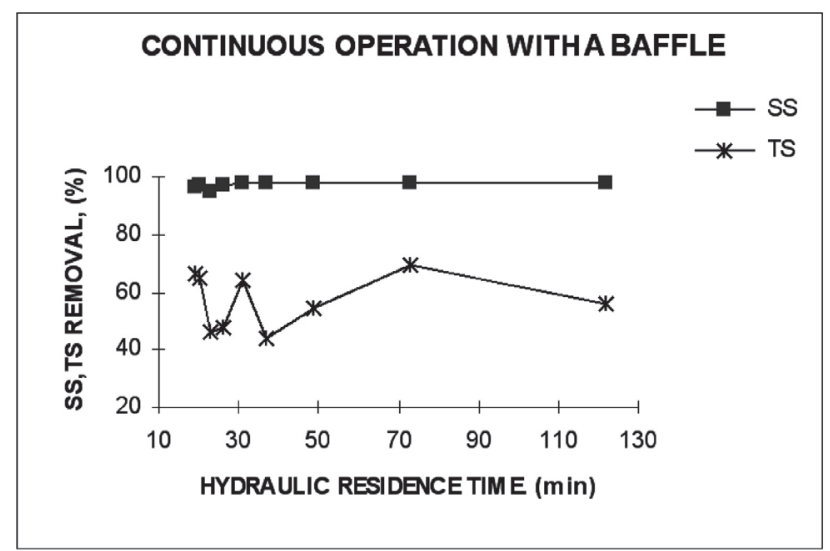

Fig. 7 Performance of EDI (Baffle) at different hydraulic residence times.

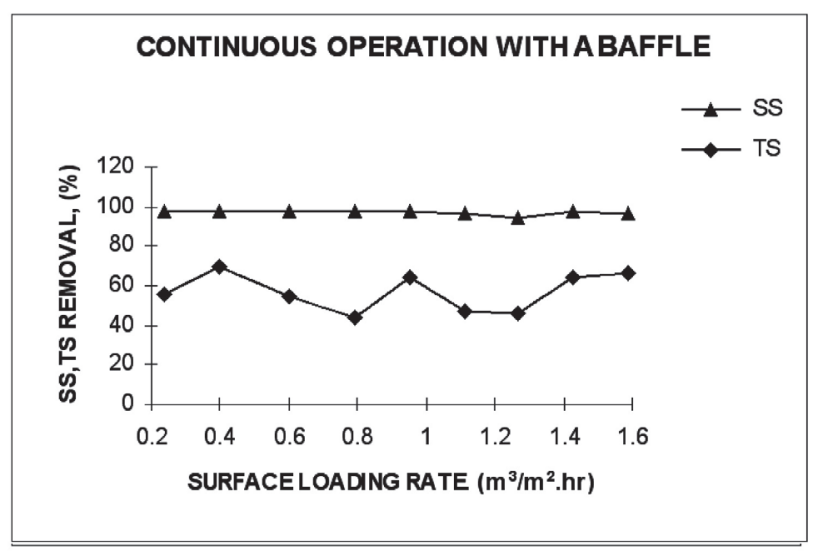

Fig. 8 Performance of EDI (Baffle) at different surface loading rates. 
2011/4 PAGES $1-11$

are similar to those observed in the conventional sedimentation tank regarding the percentage removal of SS and TS in relation to the HRT and SLR. In these mathematical model runs on the upgraded sedimentation tank, similar observations to those made during the experiments on the conventional sedimentation tank were evident regarding the trends in TS, BOD, and COD removal.

\subsection{Comparison between Conventional and EDI (Baffle) Sedimentation Tanks}

In order to perform such a comparison, the removal efficiency for SS has been determined for both types of settlers at five different influent flow rates ranging from $150 \mathrm{~m}^{3} / \mathrm{h}$ to $350 \mathrm{~m}^{3} / \mathrm{h}$. Comparing the results obtained from operating the mathematical model of the tank as a conventional sedimentation basin and as a high rate settler (EDI), i.e. without the EDI (baffle) and with the EDI (baffle), it is apparent that during an operation with the EDI (baffle) the efficiency

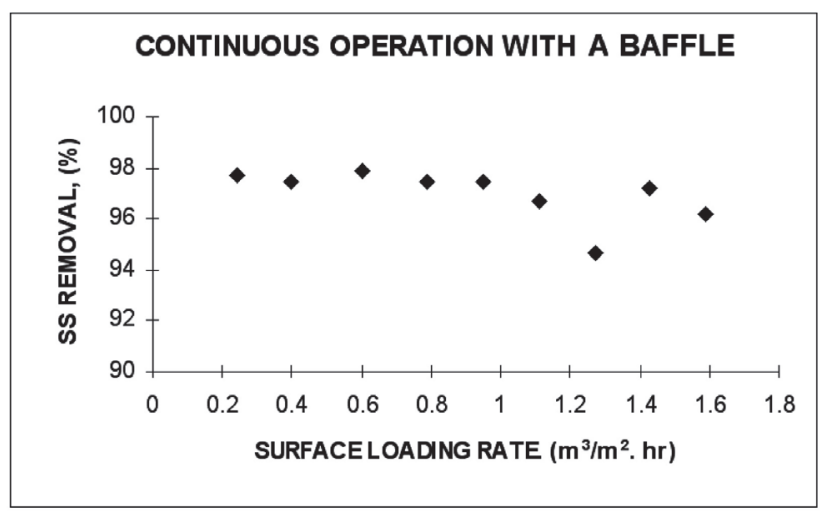

Fig. 9 Effect of surface loading rate on SS removal of EDI (Baffle).

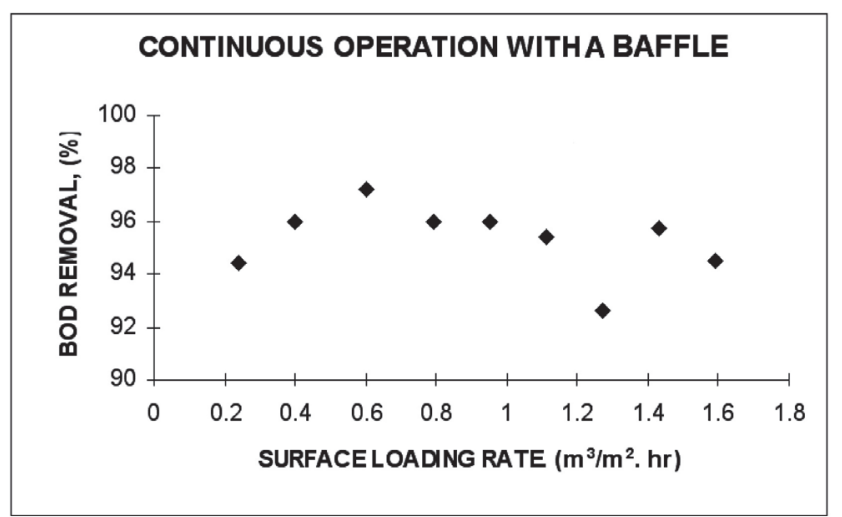

Fig. 10 Effect of surface loading rate on BOD removal of EDI (Baffle).

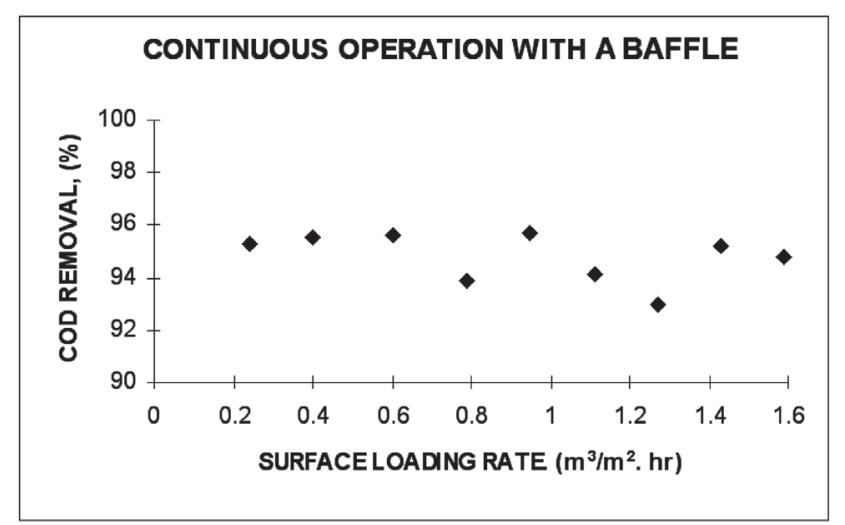

Fig. 11 Effect of surface loading rate on COD removal of EDI (Baffle).

of the SS removal is better than in case of conventional tank by $2 \%$ - $3 \%$, which is a marginal increase in efficiency. However, the tank with an EDI (baffle) was capable of maintaining high removal efficiencies even when the biological solids had a high SVI as shown in Tables $\mathbf{1}$ and 2, knowing that high SVI values $(>200 \mathrm{ml} / \mathrm{g}$ ) are indicative of poor sludge settleability.

The merits of the EDI (baffle) is more apparent when settling rather than thickening is controlling the tank design. This may indicate that the application of an EDI (baffle) in the secondary clarification of biological sludge may not be as advantageous as its application in the primary clarification of wastewater solids. However, when secondary clarifiers are overloaded or suffer from rising sludge problems, upgrading of such clarifiers using an EDI (baffle) is definitely advantageous. This is in addition to savings in costs of land area covered by settlers which is much less in case of an EDI (baffle) than in case of conventional type gravitational settling tanks. Based on the results obtained for the EDI (baffle), a statistical model could be formulated by applying a linear regression analysis to the relationship between the SLR and \% SS removal. Figures 9, 10, and 11 illustrate the relationship obtained which could be expressed by the following equation:

$\%$ SS removal $=98.26-1.39$ SLR

This is a statistical model describing the removal efficiency of SS in the upgraded EDI (Baffle). Similarly, the following equations where obtained for BOD and COD:

$\%$ BOD removal $=96.20-1.01$ SLR

$\%$ COD removal $=95.50-0.8$ SLR 


\section{CONCLUSIONS}

The following conclusions can be drawn:

1. The EDI (baffle) has proved effective in improving the performance of the secondary sedimentation of biological solids at the studied surface loading rates in a range of 0.2 to $1.6 \mathrm{~m}^{3} /$ $\mathrm{m}^{2} \mathrm{hr}$.

2. In comparison with a conventional settler, the EDI (baffle) is less affected by overloading. If the design surfaces loading rate criteria for conventional settling tanks are used for designing high-rate settlers, the latter should perform better within the range of surface loading rates normally used in practical design.

3. The efficiency of the removal of solids increases with the increase of HRT and decrease of SLR.

4. The efficiency of suspended solids removal is a better parameter for describing the performance of sedimentation tanks compared to total solids. Meanwhile, the biological transformations of solids in the secondary sedimentation tank could contribute to BOD and COD which results in higher BOD/SS and COD/ SS ratios in the effluent than in the influent. This emphasizes the uniqueness of SS as a better parameter in performance evaluation.

5. The main advantage of an EDI (baffle) in the secondary sedimentation of biological solids lies in its capability to cope with plant overloading conditions. Such settlers could be easily installed in an existing rectangular sedimentation tank as a solution to rising sludge problems at minimal cost compared to other solutions such as increasing tank depth, addition of chemical coagulants,...etc. Installation or removal of an EDI (baffle) would not interfere with the normal operation of existing sedimentation tanks.

\section{ACKNOWLEDGEMENTS}

The article has been written with the support of the TEMPUS Project 159311-2009-IT-JPCR Network for Master Training in Technologies of Water Resources Management - NETWATER and VEGA 1/1143/11 grant research tasks solved at the Department of Sanitary Engineering of the Faculty of Civil Engineering of the Slovak University of Technology, Bratislava.
Nomenclatures

\begin{tabular}{|c|c|}
\hline Symbol & Description \\
\hline $\mathrm{F}$ & $\begin{array}{l}\text { A volume force term }\left(\mathrm{N} / \mathrm{m}^{3}\right) \text { which is zero in both the } \\
\mathrm{x} \text { and y directions. }\end{array}$ \\
\hline $\mathrm{U}$ & The average flow velocity vector $(\mathrm{m} / \mathrm{s})$ \\
\hline$P$ & The average pressure $(\mathrm{Pa})$ \\
\hline$\eta$ & Dynamic viscosity (Pa.s) \\
\hline$\rho$ & Density $\left(\mathrm{kg} / \mathrm{m}^{3}\right)$ \\
\hline$t$ & Time (s) \\
\hline $\mathrm{C}_{\mu}$ & A model constant \\
\hline$\vec{k}$ & The turbulent kinetic energy $\left(\mathrm{m}^{2} / \mathrm{s}^{2}\right)$ \\
\hline$\varepsilon$ & The dissipation of turbulent energy $\left(\mathrm{m}^{2} / \mathrm{s}^{3}\right)$ \\
\hline $\mathrm{C}$ & The concentration of solids (mg/l) \\
\hline $\mathrm{U}_{\mathrm{s}}$ & The settling velocity $(\mathrm{m} / \mathrm{s})$ \\
\hline$\sigma_{\mathrm{c}}$ & The Schmidt number $(0.7)$ \\
\hline$v_{\mathrm{t}}$ & The turbulent viscosity \\
\hline $\mathrm{U}_{\mathrm{so}}$ & The reference settling velocity $(\mathrm{m} / \mathrm{s})$ \\
\hline $\mathrm{r}_{\mathrm{h}}, \mathrm{r}_{\mathrm{p}}$ & $\begin{array}{l}\text { Induce the domination of the first and the second term } \\
\text { for the falling and the rising part }\end{array}$ \\
\hline $\mathrm{C}_{\mathrm{ns}}$ & The nonsettleable concentration (mg/l) \\
\hline $\mathrm{C}_{\mathrm{D}}$ & The drag coefficient \\
\hline$\rho$ & The fluid density $\left(\mathrm{kg} / \mathrm{m}^{3}\right)$ \\
\hline $\mathrm{V}_{\mathrm{t}}$ & The blade-to-fluid relative velocity $(\mathrm{m} / \mathrm{s})$ \\
\hline A & The scraper displacement area $\left(\mathrm{m}^{2}\right)$ \\
\hline CFD & Computational Fluid Dynamics \\
\hline RTD & Residence Time Distribution \\
\hline SS & Suspended Solids \\
\hline TSS & Total Suspended Solids \\
\hline EDI & Energy Dissipating Inlet \\
\hline HRT & Hydraulic Retention Time \\
\hline BOD5 & Biochemical Oxygen Demand \\
\hline TVS & Total Volatile Solids \\
\hline COD & Chemical Oxygen Demand \\
\hline VSS & Volatile Suspended Solids \\
\hline SOR & Surface Overflow Rate \\
\hline Q & Discharge $\left(\mathrm{m}^{3} / \mathrm{s}\right)$ \\
\hline
\end{tabular}




\section{REFERENCES}

[1] Krebs, P. (1991). The hydraulics of final settling tanks, Wat. Sci. Tech., 23 Kyoto, 1037-1046.

[2] Dahl, C. Larsen, T. \& Petersen, O. (1994). Numerical modelling and measurement in a test secondary settling tank, Wat. Sci. Tech. 30(2), 219-228.

[3] Krebs, P. Vischer, D. Gujer, W. (1995). Inlet-structure design for final clarifiers, Journal of Environmental Engineering, 121(8), 558-564.

[4] Brouckaert C.J. Buckley C.A. (1999). The use of computational fluid dynamics for improving the design and operation of water and wastewater treatment plants. Wat. Sci. Tech., 40(45), pp. 81-89.

[5] Lakehal D., Krebs P., Krijgsman J. Rodi W. (1999). Computing shear flow and sludge blanket in secondary clarifiers. J. Hydr. Engrg., 125(3), pp. 253-262.

[6] Jayanti S. Narayanan S., (2004). Computational study of particle-eddy interaction in sedimentation tanks, J. Environmental Eng., 130 (1), 37-49.

[7] Ghawi A. Hadi Jozef Kris (2007a).” Design and Optimization of a Sedimentation Tank in Slovakia with CFD Modeling" 10th International Symposium on Water Management and Hydraulic Engineering 2007 with special emphasis on the impact of hydraulic engineering construction on the environment, 4 - 9 September 2007. Šibenik, Croatia
[8] Ghawi A. Hadi, Jozef Kris (2007b). A Numerical Model of Flow in Sedimentation Tanks in Slovakia, Third International $\mathrm{PhD}$ Symposium in Engineering, 25-26 October 2007, Hungary University of Pollack Mihály Faculty of Engineering, Pécs, Hungary

[9] Ghawi A. Hadi, Jozef Kris (2007c). Improved, Modeling, Simulation and Operational Parameters of Settling Tank. 6th International Conference of $\mathrm{PhD}$ Students, University of Miskolc, Hungary, 12- 18 August 2007, pp. 69-75.

[10] APHA (1989), "Standard Methods for the Examination of Water and Wastewater," 17th edition, American Public Health Association, Washington, D.C.

[11] Wilcox D.C., Turbulence Modelling for CFD, DCW Industries, Inc., La Canada, California, (1998).

[12] Pollert, J. ml., Pavlíčková, I., Todt, V.: Optimalizace dosadzovacích nádrží ÚČOV Praha matematickým modelem (Optimalization of secondary clarifier Praha by thee mathematical model). In: Městské vody, 2010, Brno, ARDEC, 2010, 113-121, ISBN 978-80-8602071-6.

[13] Pollert, J. ml., Koníček, Z., Thoeye, Ch., Boonen, I., Gunther, P.: Optimalization of secondary clarifier using $3 \mathrm{D}$ modeling of sludge. In: World Water congress and Exhibition - Abstracts. Oxfod: IWA, 2008. 